\title{
Unmet social needs and teenage pregnancy in Ogbomosho, South-western Nigeria
}

\author{
Kabiru K Salami, Matthew Ayegboyin, Isaac A Adedeji
}

Department of Sociology, University of Ibadan, Ibadan Nigeria

\begin{abstract}
Background: Consistent high teenage pregnancy rates in South-western Nigeria are characteristically underpinned by the unmet social needs of the teenagers.

Objective: To elicit intergenerational views on the influence of unmet social needs on teenage pregnancy.

Methods: Through a descriptive and cross-sectional design, a total of 174 respondents who were either pregnant teenagers, teenage mothers during the survey or had been pregnant as teenagers, were interviewed, using questionnaire supplemented with 12 key informant interviews.

Results: With the mean age of 16.5 years, and educational status range of between primary and below $(25.8 \%)$ and tertiary $(9.8 \%)$ levels, only $39.7 \%$ respondents were married, about half $(47.7 \%)$ remained single while others were separated $(12.6 \%)$. Less than half $(44.9 \%)$ of the respondents were engaged in occupational activities. The unmet material and financial supports expected from parents $(43.1 \%)$, the lack of free education from government up till secondary school level $(51.2 \%)$, the lack of sex education and knowledge needs for signs of maturity $(53.4 \%)$ and discouragement from friends not to have boyfriend $(66.1 \%)$ prone teenagers to unplanned pregnancy.
\end{abstract}

Conclusion: Promotion of sexual education and parental care is encouraged as strategy against unplanned pregnancy among teenagers.

Keywords: Unmet needs, pregnancy resolution, teenagers, Nigeria

DOI: http://dx.doi.org/10.4314/ahs.v14i4.27

\section{Introduction}

Teenage period is characteristically a transition stage when individuals become sexually active ${ }^{1}$. Usually less than 20 years but greater than 13 years ${ }^{2}$, teenagers are unquestionably at a vulnerable development stage where they attempt to navigate the sensitive transitions from childhood to adolescence ${ }^{3}$, the stage which is also characterized by increase in personal control, responsibility and independence. Teenagers frequently negotiate and adjust to increased demands of a more autonomous lifestyle hence reactions to societal sexual norms and expectations become the key tasks of teenagers $^{4}$. As teenage pregnancy may be grounded by social and economic factors ${ }^{5}$, its maintenance may be jeopardized with physical and emotional pressure ${ }^{6}$, hence conscientiously contributing to poverty cycle ${ }^{7}$. The decision to keep the pregnancy could also be unavoidably influenced by social, economic and cultural factors such

\section{Corresponding author: \\ Kabiru K. Salami, \\ Department of Sociology \\ University of Ibadan, Nigeria \\ Email:kabsalami@yahoo.co.uk}

as the level of education, socialization, family acceptance and support of the affected mothers ${ }^{8,9}$.

Despite the downward trend in teenage fertility rate globally, approximately 1.5 million girls got married before they attained age $15^{10}$ and about 18 million girls aged 10-19 years give birth on yearly basis 7 . It was revealed that $75 \%$ out of the yearly teen births are intended and planned ${ }^{7}$ and $90 \%$ of adolescent pregnancies in the developing world are owned to married teenage girls ${ }^{10}$ due to encouragement received from their husbands and in-laws for early pregnancies ${ }^{11}$. Evidences have shown that data on teenage pregnancy in Nigeria does not only account for high birth rate for teenagers, but that the incidence of pregnancy among female teenagers in Nigeria is increasing rapidly ${ }^{12,7}$. This may be attributed to low success of government policies and strategies concerning the sexual and reproductive health of teenagers in Nigeria ${ }^{13}$, hence, there is no gainsaying that 'unmet need' for contraception is popular for its potential in determining the maximum demand for family planning services. Becker ${ }^{14}$ positioned that 'unmet need' originally referred to "married women who do not want a birth in the future but are not practicing contraception". The definition later stooped and 
broadened to accommodate married women (nonus- the life of indebtedness ${ }^{16}$, and more closely, the

ers) who want a future birth. The debate continues and experiences of teenage pregnancy in three succesin fact, unmarried women have been included in some analysis ${ }^{14}$. sive generations ${ }^{17}$. Intrinsically, the potential for understanding patterns of stability and change in all types of social systems is exceedingly exponential through Significantly, the expansion in the definition of 'un- life course perspective. One complicated concern is met need' has also introduced, defined and studied that family roles must often be synchronized acros "men's unmet need" as well as "couples' unmet need"14. three or more generations at once, even though the According to Becker ${ }^{14}$, "the concept of unmet need is synchronization does not go smoothly. However, just that - a concept". By taking the advantage of the Huinink and Feldhaus ${ }^{18}$ observed that life experiences concept, the tradition of 'unmet needs' is modified in such as divorce, remarriage, and discontinuities in parthis article as "unmet social needs" to describe the in- ents' work and educational trajectories may conflict with dividual's deprived social needs; a combination of ex- the needs of children such as in career building, family ternal materials, social, emotional, skills acquired, and and work transitions ${ }^{18}$. The "generation in the middle" financial resources at one's instances to promote well- may have to make uncomfortable choices when allocatbeing. "Unmet social needs" here describes the func- ing scarce economic and emotional resources. When tional limitations of social and instrumental activities a significant life event in one generation is juxtaposed for daily living. As needs of teenagers flow from ben- with a significant life event in another generation, famiefactors such as the family, society, government and lies and individual family members are especially vulself; these needs, most often, are not provided nerable ${ }^{19}$. Thus, the risky sexual behaviour of teenagto the level of expectation. In spite of this, studies ers is closely linked to their previous life experiences. that have shown a range of needs for teenagers ${ }^{9}$ have Pregnancy experience of teenagers is interpreted in thi not yet examined how unmet social needs have study based on their unmet social needs. The motive served as catalyst for unplanned pregnancy among of behaviour of an individual or group of people can teenagers in a south-western urban community in Ni- be attributed to interpretative understanding in terms geria. This study hinges on the life course perspective. of the subjective meanings of social conditions; The life course perspective emphasizes the importance therefore the tendency for a teenager to respond to a of historical contexts of previous life events to proper condition is based on the subjective implications of understanding of transformation in individual's life. such condition.

\section{The perspective portends that the influence of life Methods and materials}

events and chances that individuals are exposed to are Ogbomosho, the second largest city in Oyo State and different because of their different life cycles, socio- the 12th largest city in Nigeria with a population of 726 , economic status and opportunities among others ${ }^{15}$. $300^{20}$ was the site of this study. Ogbomosho being one The life course perspective also draws on the aspect of the major towns in Oyo State comprises two of traditional theories of developmental psychology, Local Government Areas: Ogbomosho North and which look at the events that typically occur in people's Ogbomosho South and lies on a longitude $8^{\circ} 15$ North lives during different stages. However, the life course Eastward from Ibadan, the capital city of Oyo State. perspective differs from the psychological theories in Inhabitants are Yoruba and are largely small scale velopmental psychology looks for universal, predict- on part-time basis. Data for this paper was generated able events and pathways, the life course perspective from a larger study that documented intergeneracalls attention to how historical time, social location, tional views of three successive generations conand culture affect the individual experience of each life cerning teenage pregnancy in a South-western commustage.

nity in Nigeria ${ }^{17}$. The views of 174 female respondents comprising 116 pregnant teenagers, 35 teenagers who The attention of the life course perspective is more had given birth and 23 mothers, who gave birth in their important in intergenerational studies. Although the teen years, are documented here. The diversity of the perspective is still relatively young, its popularity is grow- sample was significantly intended to capture the ing. In recent time, it has been used to understand generational, historical and experiential dimensions of unmet social needs. There was purposive selection of 20 streets, followed by snowballing approach to select respondents who were willing to participate in the study. On meeting the potential respondents, efforts were made by the researchers to explain the purpose of the study and sought for the consents of the respondents to participate in the study. On daily basis, administered copies of the questionnaire were edited, coded and stored in a safe place where no other person than the researchers can access. The Statistical Package for the Social Sciences (SPSS) was used to analyse the quantitative data generated in this study.

In addition, there were twelve key informant interviews among teenagers conducted in another part of the community different from the streets that were sampled for the quantitative data in this survey. Informants were met at their respective homes and interviewed with a standardised interview guide.

Table 1: Socio-demographics of respondents

Variables $(\mathbf{N}=174)$

With the approval of the informants, responses were written as well as tape-recorded. These were later transcribed and analysed with the use of content analytic tool. Results from the quantitative data were supplemented with the data from qualitative aspect and inferences were made.

\section{Results}

As shown in Table 1, overall $66.6 \%$ of the respondents were within the age range of $10-14$ years, 35 (20.1\%) of the respondents were between age 15 and 19 years while $23(13.3 \%)$ respondents fell within the age range of 20 years and above, altogether indicating the majority of the respondents as teenagers. Respondents' level of education ranged between primary school level and below $(25.8 \%)$ and tertiary institution level $(9.8 \%)$. Less than half $(45.4 \%)$ of the respondents were Muslims, (lightly above half, $89(51.2 \%)$ were Christians while six (3.4\%) respondents belong to African traditional religions.

\begin{tabular}{|c|c|c|c|}
\hline & Variables $(\mathrm{N}=174)$ & Frequency & Percentage \\
\hline \multirow{2}{*}{$\begin{array}{l}\text { Age of } \\
\text { respondents }\end{array}$} & 10 - 14 years old & $\begin{array}{l}116 \\
35\end{array}$ & $\begin{array}{l}66.6 \\
20.1\end{array}$ \\
\hline & $\begin{array}{l}15-19 \text { years old } \\
20 \text { years and above }\end{array}$ & 23 & 13.3 \\
\hline Highest & Primary and below & 45 & 25.8 \\
\hline Educational & Junior secondary school & 44 & 25.3 \\
\hline \multirow[t]{2}{*}{ Qualification } & Senior secondary school & 68 & 39.1 \\
\hline & Tertiary & 17 & 9.8 \\
\hline \multirow[t]{5}{*}{ Religion } & Islam & 79 & 45.4 \\
\hline & Indigenous religion & 6 & 3.4 \\
\hline & Christianity: Protestant & 24 & 13.8 \\
\hline & Catholic & 13 & 7.5 \\
\hline & Pentecostal & 52 & 29.9 \\
\hline \multirow[t]{3}{*}{ Occupation } & Not employed & 34 & 19.5 \\
\hline & Student & 62 & 35.6 \\
\hline & Trading & 45 & 25.9 \\
\hline & Others* & 33 & 19.0 \\
\hline
\end{tabular}

* Others include: artisans and civil servants 
列 more than two-third $(86.7 \%)$ of them were pregnant while $13.3 \%$ were nursing children as at the time of survey.

The unmet social needs of teenagers before preg nancy period.

The unmet social needs of teenagers were categorized into four according to the expected sources of support to meet their needs as shown in Table 2: (1) Family: these are needs that family members such as the father, mother or senior siblings can provide (2) Self: these are in form of knowledge and skills and selfefficacy that teenagers ought to have possessed at the stage (3) Society: These are teenagers' needs expected to be provided by the community and 4) Government: These are supports expected to be provided to the teenagers by the government. Table 2 shows that parents' inability to provide for children both financially and materially (43.1\%) was rated highest while inability to provide needful restriction against peer influence

\section{Table 2: Unmet social needs of Teenagers}

\begin{tabular}{|c|c|c|c|c|}
\hline Unmet Social Needs & & $\begin{array}{l}\text { efore } \\
\text { gnancy }\end{array}$ & & $\begin{array}{ll}\text { Iring } \\
\text { nnancy }\end{array}$ \\
\hline Familial & Number & Percent & Number & Percet \\
\hline $\begin{array}{l}\text { Parents' enthusiasm to discuss sexuality } \\
\text { Provision of needful restriction against peer }\end{array}$ & 29 & 16.6 & - & - \\
\hline influence & 21 & 12.1 & - & - \\
\hline $\begin{array}{l}\text { Parents' ability to provide for children materially } \\
\text { and financially }\end{array}$ & 75 & 43.1 & 89 & 51.1 \\
\hline Maintenance of happy and unbroken homes & 49 & 28.2 & - & - \\
\hline Non-abusive words by parents and relatives & - & - & 55 & 31.6 \\
\hline Family'senthusiasmto acceptpregnancy & - & - & 30 & 17.3 \\
\hline$\underline{\text { Strongbelief inself-will }}$ & - & - & 20 & 11.5 \\
\hline
\end{tabular}

\section{Societal}

Discouragement from friends from having

boyfriends

Awareness about sexulity in church/mosque

66.1

General level of povert

Acceptance by society without shame

Enthusiasm by person responsibleforpregnancy

\section{Government}

Free education to secondary school level

Little provision of emergency contraceptives

Availability of functional counseling unit in schoo

Stiff penalty for the 'runaway' boy

Provision of vocational training

Acceptance of teenagers by the school

Free access to antenatal clinics

Positive behavior by nurses

Free medical treatment (a) to start primary school early and inability to discourage self from pornography. Lack of discouragement from friends not to have boyfriends was reportedly 列 . $9 \%$ ) Other unmet social needs as shown in Table were attributed to government's laxity.

Table 2 also highlights the unmet social needs for the furing pregnancy period. Data showed that ilies were unable to make financial and material prons available to the pregnant teenagers (51.1\%), yet expectedly, abusive words were used on the pregnan teenagers by parents and relatives $(31.6 \%)$ and in fact families were reluctant to accept pregnancy $(17.3 \%)$

$\begin{array}{cccc}5 & 2.9 & 46 & 26.4 \\ 54 & 31.0 & -\end{array}$

$\begin{array}{ll}67 & 38.5\end{array}$

$61 \quad 35.1$

$\begin{array}{ll}89 & 51.2 \\ 32 & 18.4\end{array}$

$15 \quad 8.6$

18.4
8.6

\begin{tabular}{ll}
- & - \\
38 & 21.8 \\
32 & 18.4 \\
35 & 20.1 \\
36 & 20.7 \\
43 & 24.7 \\
28 & 16.1 \\
\hline
\end{tabular}

African Health Sciences Vol 14 Issue 4, December 2014
In addition, Table 2 shows that teenagers in this study I have to satisfy his sexual urge. At last, I got pregnant". were reportedly constrained to further their education Even as a pregnant teenager, informants reiterated during pregnancy; lacked balanced diet; had inadequate the challenges faced during the period they were pregcommunication with their parents; and lacked self nant. Expressions by the teenagers indicated rejection confidence in doing things. Moreover, teenagers also from various sources, inability to continue school prolacked acceptance from society, and at the same grams due to social deprivation that they faced in school time were neglected by persons responsible for the and even the embarrassment received from the nurses pregnancy. Table 2 also reports the unmet social needs during the an of teenagers from the government. was like jumping from 'frying pan to fire'. I faced total rejection from my parents. I was left alone to cater Contextually, Teenagers who were informants ex- for myself even when my boyfriend had fled. I had to pressed dismay in the inaccessibility to materials, skills, move to his father's place, yet there was no one to cater and financial resources that were necessarily needed for me there because he had already lost his mother. I at the age. Teenagers were reportedly exposed to the dropped out of school because of the embarrassment dangers that pornographic books and television pro- in the school for being pregnant. I almost delivered my grams which portrayed risky sexual behaviour promote. baby at home since I did not register for ANC because One informant, a pregnant teenager, put the blame on I was afraid that the nurses would shout at me for being the lack of restriction to the uncensored pornographic a teenager."

materials that are released to the public. In her whe

"...we did not have the knowledge that it was not proper for us to get used to watching sex film, and reading comic magazines that expose ladies' bodies. Unconsciously, we tried out some of the behaviours that we already familiarized with. It was too late for us to realize that we were too young for having sex".

Level of education and pregnancy resolution

The study tested the influence of education of the respondents on the actions taken soon as they were aware of their pregnancy. Table 3 reveals an association between the educational status of the respondents and the first action taken. The chi-square value was high $(56.5 \%)$ and greater than the tabulated value at $\mathrm{P}<0.05$ Another teenager explained how she had to negotiate indicating an association between educational level and sex for material things with her boyfriend. According the first action taken by the respondents on pregnancy. to her, "What can you do when your parents do not In all, five possible actions were presented: "consult a help you with all the necessary materials you need? The doctor", "inform parents", "consult peers for advice help I was getting from my boyfriend was based on "give about pregnancy", and "drop out of school". The reand take'. And I did not want to be mischievous hence sults show that slightly below half $(43.5 \%)$ of the teen

\section{Table 3: Actions taken by respondents as influenced by educational status}

Educational Status* First action taken by respondents

Consult a Inform

doctor parents Consult peers Abortion of school Total

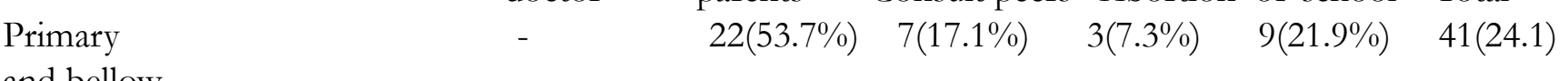

and bellow

JSS

$\begin{array}{llllll}9(20.5 \%) & 18(41.0 \%) & 8(18.2 \%) & 7(16.0 \%) & 2(4.5 \%) & 44(25.9 \%)\end{array}$

$\begin{array}{llllll}20(29.4 \%) & 34(50.0 \%) & 9(13.2 \%) & 5(7.4 \%) & - & 68(40.0 \%)\end{array}$

Tertiary

$(17.6 \%)-3(17.6 \%)-3(17.6 \%)-17(10.0 \%)$

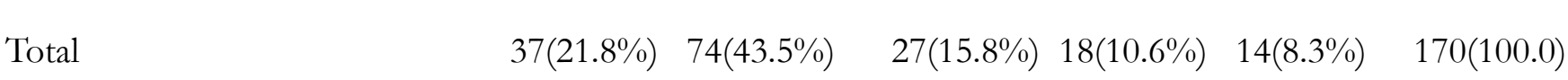

*JSS=Junior Secondary School, SSS= Senior Secondary School, Tertiary includes: National

College of Education, Ordinary National Diploma, and Higher National Diploma

Chi Square Value $=56.47^{* *} \mathrm{P}<0.05$

African Health Sciences Vol 14 Issue 4, December 2014 
mothers "informed their parents" first than the 21.8\% of them that "consulted a doctor" first to confirm the pregnancy before other actions were taken. Respondents who were holders of "school certificate" $(50 \%)$ or those who held below "school certificate", informed their parents first, about their pregnancy. The results indicate that once the level of education increases above the school certificate, teenagers therefore have tendency of consulting a doctor first than taking other actions as shown in Table 3 .

Perceived resolution of the unmet social needs for teenagers

Numerous perceived approaches were identified as means of tackling teenagers' unmet social needs. Approaches such as: "good counselling/proper monitoring by parents and teachers", "parents' adequate care of children" "provision of free education by government" and "abstinence from sexul intercourse till marriage" were highlighted by the teenagers. Other approaches including; praying for children and teenagers by people around them; advising teenagers to study hard; and staying away from guys and harkening to parental advice, were also revealed as shown in Table 4.

Table 4: Perceived Resolution of Unmet social needs for Teenagers

\begin{tabular}{|c|c|c|}
\hline Perceived resolution factors & Frequency & Percentage \\
\hline Good counseling/proper monitoring & 22 & 12.6 \\
\hline $\begin{array}{l}\text { Parents to talk about sex with } \\
\text { their children }\end{array}$ & 9 & 5.2 \\
\hline Proper parental care & 36 & 20.7 \\
\hline Praying for them & 4 & 2.3 \\
\hline Hard studies & 7 & 4.0 \\
\hline Free education & 13 & 7.5 \\
\hline Proper youth forum on sex education & 51 & 29.3 \\
\hline Hearken to parents' advice & 3 & 1.7 \\
\hline Abstinence & 12 & 6.9 \\
\hline Stay away from guys & 8 & 4.6 \\
\hline Teaching children the way of God & 9 & 5.2 \\
\hline Total & 174 & 100.0 \\
\hline
\end{tabular}

Among others, as presented in the table, proper youth programmes ${ }^{10}$ yet not much success has been recorded forum on sex education $(29.3 \%)$ ranks highest. This was due to the unpredictable nature of teenage behaviour. followed by proper parental care (20.7\%) while hearken to parents' advice $(1.7 \%)$ ranks lowest.

\section{Discussion} Teenage stage is the most sensitive transition that is risky sexual behaviour for teenagers. The fact that characterised with experimenting and exhibiting con- the needs were demanded from the parents, society firmatory and contradictory behaviours that tend to and institutions such as government, clearly positioned make or mar teenagers' future. Findings in this study the different groups of social categories as indispensahave shown some of the regular needs of teenage girls ble in the discus of life courses.

with associated limited sources opened to them, which The range of educational level attainment by teenagin most cases not sufficient to meet their needs. Re- ers as shown in this study (with about $9.8 \%$ of the results from this study indicate that the unmet social spondents that acquired formal education above secneeds of the teenagers have much implication on the ondary level) incidentally, may impact negatively on the reproductive health of teenage girls and by extension knowledge and exposure towards reproductive health can lead girls into unwanted pregnancy in an attempt to information. The influence of educational level of negotiate their needs. Teenage pregnancy is a global the respondents confirmed the position of Makinwaconcern $^{10,8}$ and has received attention through focused Adebusoye ${ }^{21}$ asserting that little or no education could be an effective facilitator of unmet social needs for early pregnancy and marriage on the one hand and on the other hand, could decrease the ability to earn better income. This is in line with the results from NDHS ${ }^{22}$ which indicated that 'low level of education' is one of the unmet social needs factors militating teenagers. Likewise, the trend of actions taken by the respondents, as influenced by their educational status, reveals that low level of education could be a pull factor of unmet needs; however, teenagers with education above 'secondary school' have the tendency to 'consult doctors' than their counterparts below their level. This position confirmed the finding by Rosen, Murray and Moreland $^{23}$ that 'teenagers with more education consult doctors first whenever they are pregnant'

Parents' reluctance to discuss sexuality (16.6\%) with their children can only influence teenagers before pregnancy experience. Parental involvement is important, as shown in the Huberman's ${ }^{24}$ observation that parentchild communication on issues associated with sexuality helps children shape their understanding and future. The 'reluctance of parental involvement' is what is identified by the more than half $(53.4 \%$ ) of the respondents believing that the lack of sexual education and signs of maturity knowledge' is one of the challenges being faced by teenagers before they were pregnant. This, in addition, portends the issue of secrecy that is often being faced by Nigeria teenagers on issues of contraceptives and sexual activities ${ }^{25,26}$ hence; making teenagers to involve in sexual practices ignorantly ${ }^{27}$.

Conversely, this study shows that soon as teenagers noticed pregnancy, parental discussion on sexuality seized to be part of their unmet social needs. Importantly, however, about one- third (27\%) of pregnant teenagers affirmed that serious awareness about sexuality education should involve the churches and mosques in the campaign. Other studies ${ }^{28,29}$ have established that religion has strong effect both directly and indirectly on 'girls' sexual and contraceptive behaviour'. Also, UN$\mathrm{ESCO}^{29}$ encouraged religious leaders to be involved in sexuality education. Invariably, the respondents' attention would have shifted to their religious group, when they had lost hope in getting sexuality discussion from parents, as demonstrated in this study.

The poverty level in the community was addressed by one-third $(31.0 \%)$ of the respondents as a major facto that induced unmet social needs before they were im- pregnated. This consolidates the evidence by National Arency for the Control of AIDS (NACA) that poverty is one of the major factors that propel the transmission of $\mathrm{HIV}$ in Nigeria ${ }^{30,22}$ and it has also remained a major household problem leading to teenage pregnancy ${ }^{31}$, which invariably put Nigeria's subjective poverty level at $93.9 \%$ as observed by Onuba ${ }^{32}$. In fact, the evidence of poverty cut across all the levels of unmet social need as depicted in this study. For example, inability of parents to provide material and financial needs for their children before and during pregnancy, the lack of making balanced food diet available, and inability of government to provide free education to secondary school are all poverty-driven factors.

\section{Conclusion}

The findings of this study provide an insight on the mmediate need for concerted effort towards reducing teenage pregnancy. Teenage pregnancy is a social rather than biomedical problem, hence focused program targeted at teenagers and care givers should be integrated into family life planning education in the country. Serious sustainable awareness should be created about the negative outcome of teenage pregnancy through programs that discourage the sociocultural barriers, which prevent sexuality discussion and limited acces to information about reproductive health of teenagers. Teenagers should be exposed to the means of protecting their reproductive health while government at all levels should provide free, compulsory and qualitative education up to at least Senior Secondary School level in Nigeria.

\section{References}

Magistro, N. What life delivers. Support group help mothers of teenage parents adjust to new roles a grandmothers. 2000. Retrieved January 18, 2011 from http//www.dailynorthwestern.com.

2. Ekott, MI. Attitude of parents to their adolescent children's sexuality. A study health care workers in Calabar. Tropical Journal of Obstertrics and Gynaecology. 2003. 3. Centers for Disease Control and Prevention (CDCP).Tracking the hidden epidemics: trends in STDs in the United States. Atlanta. 2008.

4. Cupples ME, Irvine H, Bradley $\mathrm{T}$, Boohan M Reilly P, Patterson C. Teenage mothers and their peers: a research challenge. Br J Gen Pract 1998; 48:1685-6. 5. Bankole. Unwanted pregnancy and induced abortion in Nigeria: causes and consequences, New York: Guttmacher Institute. 2004.

6. Bankole, A. and Shawn, M. Removing Barriers 
to Adolescents' Access to Contraceptive Information and Services. Studies in Family Planning. 2010; Vol.41,No 2.

7. WHO. Making Pregnancy Safer. 2008. Retrieved June 14, 2013 from: www.who.int/maternal_ child adolescent/documents/newsletter/mps_newsletter_issue.

8. James, G. and Isiugo-Abanihe,U.C. Adolescents' reproductive motivations and family size preferences in North-Western Nigeria. Asian Jor of Med Sciences, 2010;2(5):218-226.

9. Esiet, AO. Adolescent sexual and reproductive health in Nigeria. Action Health Incorporated, Lagos, Nigeria. 2012. Retrieved July 6, 2013 from http:/ / www.actionhealthinc.org/publications/docs

10. WHO. Adolescent Pregnancy Fact Sheet.2012 Retrieved June 14, 2013 from: www.who.int/mediacentre/factsheets/fs364/en/index.html.

11. Anthony, OI, Joseph, OU and Emmanuel, NM. Prevalence and determinants of unmet need for family planning in Nnewi, south-east Nigeria. Int'l Journal of Medicine and Medical Sciences. 2009; Vol. 1(8), pp. 325-329. http://www.academicjournals. org/ijmms.

12. Federal Ministry of Health, Nigeria. Assessment report of the national response to young people's sexual and reproductive health in Nigeria, Federal Ministry of Health, Abuja. 2009.

13. Sedgh G, Bankole A, Okonofua F, Imarhiagbe C, Hussain R. et al. Meeting young women's sexual and reproductive health needs in Nigeria, New York: Guttmacher Institute 2009. Retrieved July 6,2013 from http://www.guttmacher.org.

14. Becker S. Measuring unmet Need: Wives, Husbands or Couples? International Family Planning Perspectives, 1999; Vol. 25, Number 4; pg 172-180

15. Fonseca, A.M. 'Determinants of Successful Retirement in a Portuguese Population'.Clinical Gerontology, 2008; 17:219-224. Cambridge: University Press.

16. Guyer JI and Salami KK. Life Courses of Indebtedness in Rural Nigeria. In Caitrin Lynch and Jason Danely (eds.) Transitions and Transformations: Cultural Perspectives on Aging and the Life Course. 2013; Page 206-217 ISBN 978-0-85745-778-3 (hardback), ISBN 978-0-85745-779-0 (institutional ebook) Berghahn Books.

17. Salami KK and Ayegboyin M (2014) Intergenerational Life Courses of Teenage Pregnancy in Ogbomosho Southwestern Nigeria. Children and Society; 2014; Vol. ;1-12.

18. Huinink, J. and Feldhaus, M. Family Research from the Life Course Perspective. International Sociology 2009; 24(3): 299-324. doi:10.1177/0268580909102910. 19. Carter, B. and McGoldrick, M. The Expanded Family Life Cycle. (3rd Edition). New York, Pearson/Allyn and Bacon. 2005; ISBN: 0-205-40981-4.

20. Wikipedia. Census Result. En.wikipedia.org/wiki/ oyo_state.2006.

21. Makinwa-Adebusoye. Insights into early marriage and girls' education in Northern Nigeria (ed.) Action Health Incorporated. 2011. AHI Lagos, Nigeria.

22. National Population Commission (NPC) (Nigeria) and ORC Macro (2009) Demographic and Health Survey, 2008, Calverton, Maryland: National Population Commission and ORC Macro.

23. Rosen, JE, Murray, NJ and Moreland S. Sexuality education in schools: the international experience and implications for Nigeria. 2004; Policy Working Paper series no. 12

24. Huberman, B. Parent-child communication: promoting sexually healthy youth. advocates for youth. Washington, DC: USA. 2008; Retrieved Jan. 11, 2012 from http://www.advocatesforyouth.org.

25. Ojo OO and Akintomide AG. Who breaks the ice in parent-child sexual communication-counselling: Implications for Adolescent Health and Development. International Journal for Cross-Disciplinary Subjects in Education (IJCDSE) 2010; Vol.1, issue 2.

26. Omigbodun, $\mathrm{OO}$ and Omigbodun, AO. Unmet need for sexuality education among adolescent girls in southwest Nigeria: A Qualitative Analysis African Journal Reprod Health 2004; 8(3):27-37.

27. Perper, K, Peterson, K, and Manlove, J. Diploma Attachment Among Teen Mothers.Child Trends, Fact Sheet: Washington, DC. 2010; Retrieved March, 2010 from http://www.childtrends.org/Files//Child_ Trends 2010_01_22_FS_DiplomaAttainment.pdf 28. Presler-Marshall, E and Jones, N. Charting the Future: Empowering Girls to Prevent Early Pregnancy. 2012. London: Overseas Development Institute and Save the Children.

29. UNESCO. International Technical Guidance on Sexuality Education: An evidence informed approach for schools, teachers and health educators.2009.

30. NACA. Guidelines for National M \& E Plan. HIV/AIDS NNRIMS Operational Plan 2007 - 2010. 2009.

31. Okunola RA and Ojo MOD. Violence against women: A study of Ikire area of Osun State Nigeria. African Journal of Social Sciences. 2012; Vol. 2 No. 2: 131 147 ISSN 2045-8460 (online).

32. Onuba I. Dealing with challenges of unemployment, poverty. The Punch Newspaper, Sept., 2. 2012. 